\title{
Nucleolar segregation during apoptosis of haemopoietic stem cell line FDCP-Mix ${ }^{1}$
}

\author{
Siegfried Reipert ${ }^{1,3}$, Gordon Bennion ${ }^{1}$, John A. Hickman ${ }^{2}$ \\ and Terence D. Allen*,1 \\ ${ }^{1}$ Department of Structural Cell Biology, Paterson Institute for Cancer Research \\ \& Christie Hospital, Manchester, UK \\ ${ }^{2}$ Cancer Research Campaign Molecular and Cellular Pharmacology Group, \\ School of Biological Sciences, University of Manchester, Manchester, UK \\ ${ }^{3}$ Current address: Institute of Biochemistry and Molecular Cell Biology Vienna \\ Biocenter, Dr. Bohr Gasse 9, A1030 Vienna, Austria \\ * corresponding author: Dr. T.D. Allen, Paterson Institute \& Christie Hospital \\ NHS Trust, Wilmslow Road, Manchester M20 4BX, UK. tel: 44-161-446 3116; \\ fax: 44-161-446 3109; e-mail: tallen@picr.man.ac.uk
}

Received 12.6.98; revised 27.10.98; accepted 27.1.99

Edited by L. Fesus

\begin{abstract}
The programmed elimination of cells during apoptosis is distinct from necrosis both morphologically and biochemically. Currently, the morphological description of apoptosis discriminates between the segregation of the nucleolus and the so called 'chromatin condensation'. The latter originates from observations of electron dense material adjacent to the nuclear envelope of apoptotic nuclei. Although there is ample evidence for an involvement of DNA in electron dense marginations, their true nature is still unknown. By studying apoptosis in FDCP-Mix, a pluripotent murine haemopoietic stem cell line, we found morphological and histochemical evidence that electron dense material at the nuclear envelope (NE) has emerged as a result of the segregation of nucleoli in association with the nuclear membrane. The remaining electron dense and homogenous bulk of the nucleolus labels for RNAse-gold, but even more intensely for DNAse-gold, and therefore could possibly be mistaken as 'condensed chromatin' in the light microscope. The labelling of the electron dense material for DNase-gold in FDCP-Mix could be explained by a migration of DNA into the bulk of the nucleoli at an early stage of cell death.
\end{abstract}

Keywords: apoptosis; nucleolus; nucleolar segregation; chromatin; electron microscopy; enzyme gold labelling; murine haemopoietic stem cells

\section{Introduction}

The segregation of the nucleolus ${ }^{1-3}$ has been observed as both drug- and metabolite-induced effects on the nucleus (for review: ${ }^{4,5}$ ), and more recently, it has been identified as a significant process during programmed cell death (apoptosis). ${ }^{6-8}$ Numerous studies have reported nucleolar segregation as part of the overall apoptotic morphology. However, the only detailed investigation of nucleolar segregation has been in an account of apoptosis in glucocorticoid treated thymocytes. ${ }^{7}$ Part of this study was to explain how the nucleolus, which is an organelle of considerable size, reduces its size significantly during cell death. Arends et al suggested a simultaneous segregation and condensation of the nucleolus, but unfortunately, presented little evidence for condensation into small spheres. In current morphological descriptions of apoptosis the nucleolar segregation is generally presented as a 'self-explanatory' term, in which the nucleolus loses volume. There is another term, which has, perhaps been used for too long in the same waynamely, 'chromatin condensation'. ${ }^{9}$ It has been established by numerous correlative light microscopic studies using DNA binding fluorophores, ${ }^{10}$ and more recently, by DNAse-gold labelling and osmium ammine staining and subsequent acid hydrolysis of RNA, ${ }^{11}$ that DNA is a major component of the electron dense material. However, the interpretation of the electron dense material as 'condensed chromatin' still begs the following questions: What is the nature of these electron dense marginations?; Which fine structural configuration of the chromatin is related to the 'condensed' stage during apoptosis?; and are there nuclear components other than chromatin which might contribute to the electron dense marginations in apoptotic nuclei?

Our studies of nuclear segregations have been performed for the murine haemopoietic stem cell line FDCP-Mix, ${ }^{12}$ either stimulated to undergo apoptosis by withdrawal of IL-3 growth factor or by drug treatment. ${ }^{13-15}$ Apoptosis has been confirmed for both etoposide-treated and IL-3 depleted cells by conventional DNA gel electrophoresis, which showed internucleosomal DNA cleavage into a 'ladder' and by electron microscopic characterisation of the overall morphology. ${ }^{15}$ The ultrastructural studies showed typical electron dense marginations adjacent to the nuclear envelope (NE), pore clustering ${ }^{11,16}$ and signs of nucleolar segregation which are regarded as hallmarks of apoptosis. ${ }^{6,8}$ The kinetics of the experimental system have been investigated by flow cytometry using the propidium/Hoechst assay, and by correlative electron microscopy, to ensure the vast majority of cells die by apoptosis rather than by necrosis. ${ }^{16}$

For FDCP-Mix cells we found morphological evidence for a nucleolar origin of the electron dense material adjacent to the NE. RNAse-gold labelling ${ }^{17-19}$ was employed in evidence for an involvement of ribonucleic acid in the electron dense material. The large contribution of DNA to the electron dense material was confirmed by DNAse-gold labelling. ${ }^{17,20,21}$ Comparison of control FDCP-Mix cells with cells in an early stage of commitment to death by etoposide treatment suggests an uptake of DNA by the bulk of the nucleolus. 


\section{Results}

FDCP-Mix cells have been characterised for their apoptotic mode of cell death after depletion of IL-3 growth factor and etoposide treatment by both the flow cytometric propidium iodide/Hoechst assay and DNA gel electrophoresis. ${ }^{15} \mathrm{~A}$ concentration of $4 \mu \mathrm{M}$ etoposide and $24 \mathrm{~h}$ incubation were chosen to obtain cell populations with an optimal ratio between apoptotic cells, necrotic cells and viable cells. This drug treatment causes about $65 \%$ apoptotic death compared to $7 \%$ necrotic death. After $24 \mathrm{~h}$ of depletion of IL-3 $71 \%$ apoptotic cells compared to $10 \%$ necrotic cells were recorded. Besides a viable population of $12 \%$ a small apoptotic subpopulation of $6 \%$ was counted. FDCP-Mix cells produce a DNA 'ladder' of integers of approximately $200 \mathrm{bp}$ after treatment with etoposide or IL-3 depletion. ${ }^{15}$ A DNA 'ladder' appears as early as $6 \mathrm{~h}$ after treatment with $4 \mu \mathrm{M}$ etoposide. ${ }^{21}$ At this stage, the morphology of most of the cells is determined mainly by cytoplasmic autolytic processes which proceed the nuclear changes. ${ }^{16}$ At later time points the numbers of apoptotic nuclei within the cell populations have increased although they are significantly lower as the flow cytometric assays would suggest. ${ }^{21}$ For studies of the nuclear segregation cell populations with an optimal ratio between apoptotic and necrotic death rather than cell populations with the highest possible number of overall death were used.

In our studies of nucleolar segregation in FDCP-Mix, we concentrated on the morphological changes of nucleoli in association with the nuclear envelope (NE). Previously, it has been established by TEM serial sectioning and threedimensional reconstruction that, with few exceptions, nucleoli are arranged in association with the NE in physiological conditions (for review: ${ }^{22}$ ). Clearly, the depth of section, local arrangement, number and size of the nucleoli influence the number of nucleoli found in association with the NE in TEM sections. For thin sections of FDCP-Mix control cells, between 50 and $70 \%$ of sectioned nucleoli display some association between the nucleolus and the NE. An interesting detail of this association is a layer of heterochromatin between the NE and the nucleolus, which is indicated by a weakly stained region in conventionally stained (uranyl acetate, lead citrate) epoxy resin sections. ${ }^{21,23}$ In Lowicryl embedded FDCP-Mix control cells the supposed heterochromatin layer (marked by arrows in Figure 1a) labels intensely for DNAse-gold. Beside this labelling of heterochromatin, DNAse-gold complexes were found at the periphery of the nucleolus, whereas the granular bulk of the nucleolus was negative for DNAse-gold (Figure 1a and b). This observation of FDCP-Mix control cells contrasts with DNAse-gold labelling for viable etoposide treated FDCPMix cells. After $24 \mathrm{~h}$ of treatment with $4 \mu \mathrm{M}$ etoposide, all viable cells showed additional labelling for DNA in the bulk of the nucleoli, which mainly consisted of granular components (Figure 2). For cells at this stage of the death programme, the nucleoli still appeared to be structurally intact and were frequently associated with the NE. At this stage also the nucleus displayed no morphological changes typical for apoptosis. Consequently, it seems likely that membrane associated nucleolar material is able to accumulate large amounts of DNA during apoptosis-and this process starts at an early stage. This progresses to an electron dense margination adjacent to the NE of the apoptotic nucleus, which was intensely labelled by DNAsegold (Figure 3). Given that the electron dense marginations appear as a result of functional and structural alteration of the nuceloli during apoptosis, then segregation processes

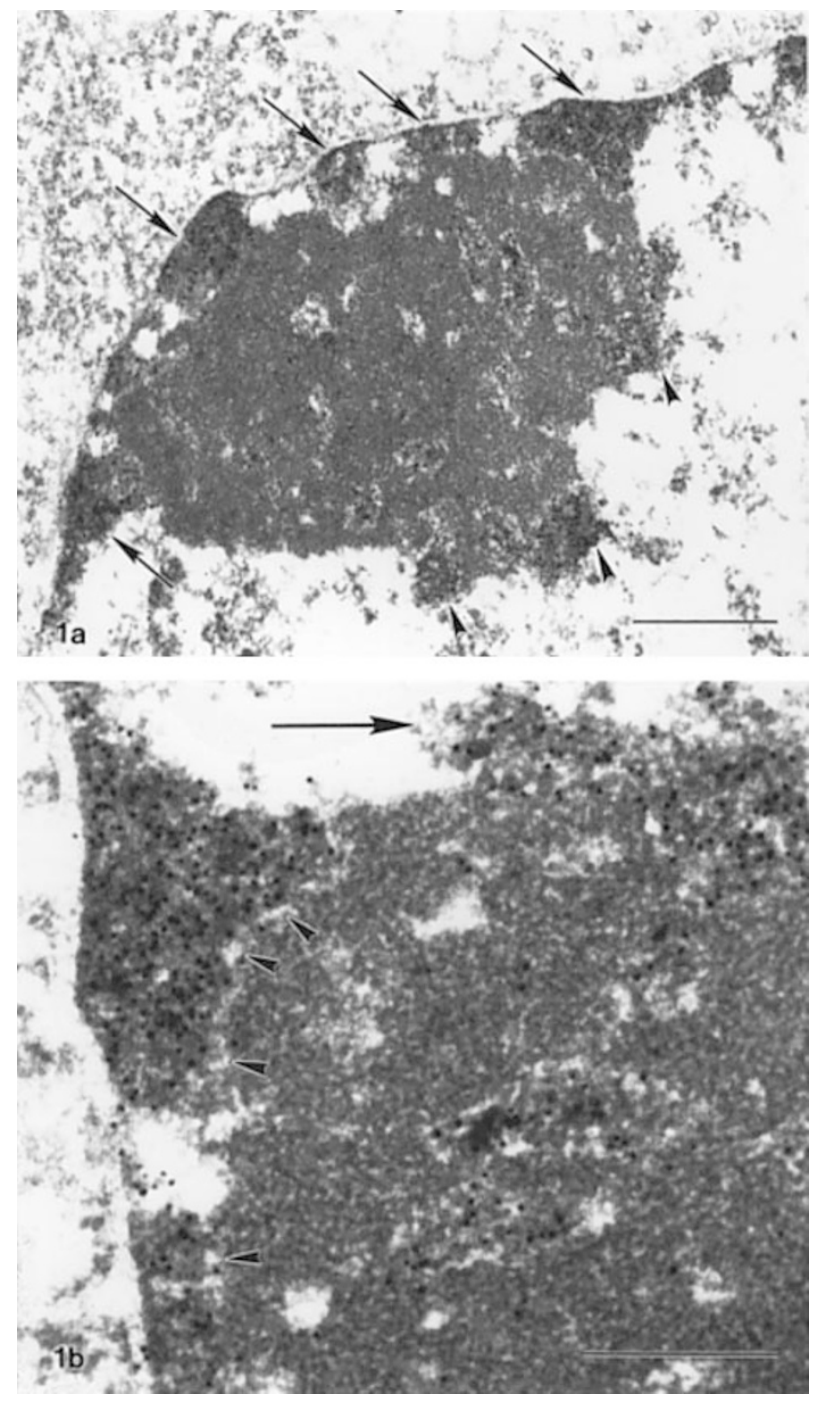

Figure 1 FDCP-Mix Control, Lowicryl section with DNAse-gold labelling in area of nucleolus in association with the NE. (a) DNAse-gold labels the heterochromatin attached to the NE (arrows) and the chromatin at the periphery of the nucleolus (arrowheads). The granular components of the nucleolus show no gold labelling. Contact between the nucleolus and the NE is mediated by heterochromatin bridges (arrows) which are labelled for DNA. Heterochromatin-free 'pockets' are located between these sites which can frequently be observed in conventional epoxy resin sections to contain many nuclear pore complexes. Reduced membrane preservation is a characteristic of Lowicryl fixation and embedding, precluding visualisation NPCs in this specimen. Bar, $1 \mu \mathrm{m}$. (b) Detail of (a) which demonstrates the sharp border (marked by arrowheads) between the heterochromatin and the bulk of the nucleolus in both DNAse-gold labelling and morphology. With exception of some discrete chromatin fibres which may enter the nucleolus from its periphery (arrow), the bulk of the nucleolus is not labelled for DNA. Bar, $500 \mathrm{~nm}$ 

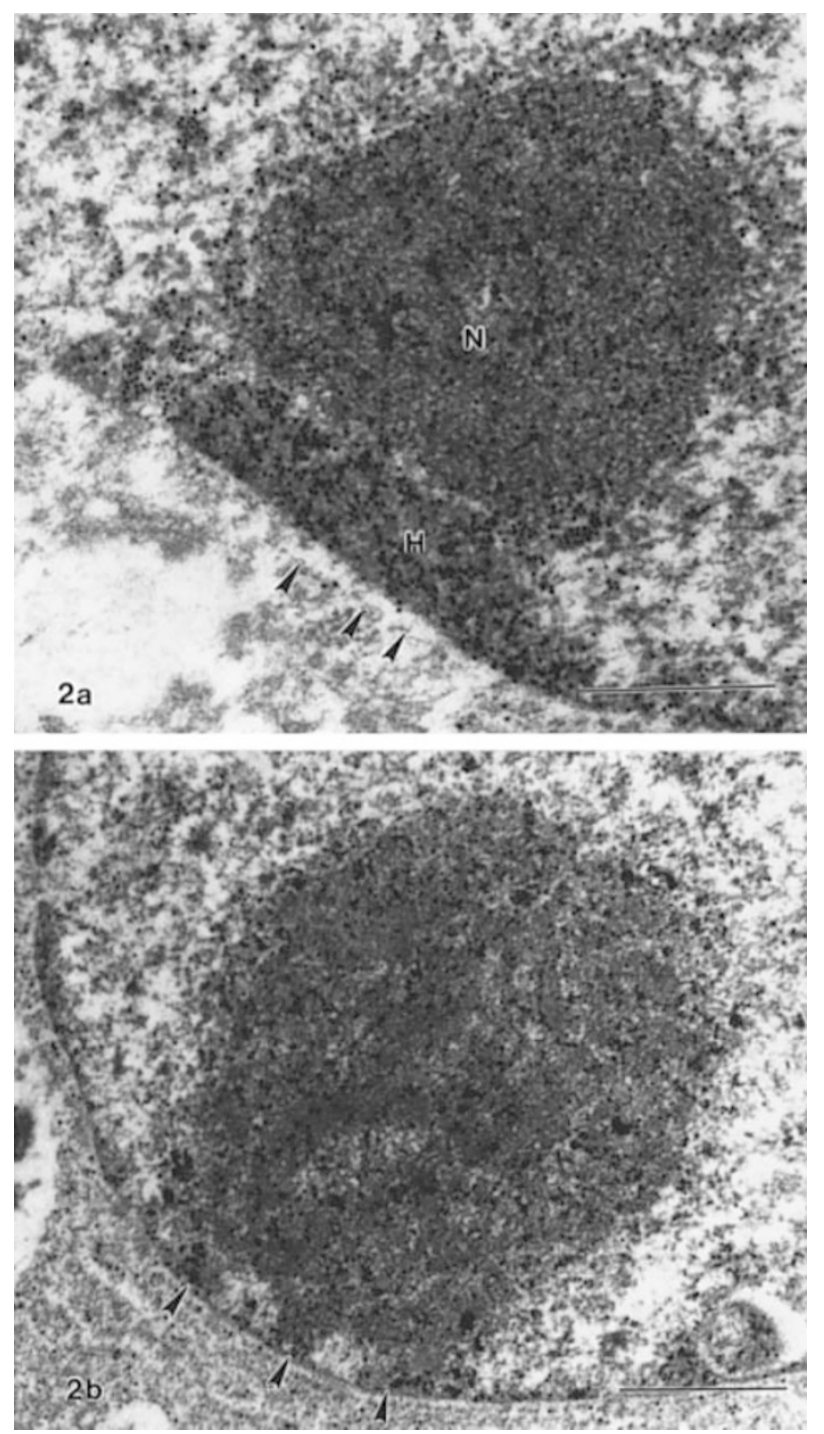

Figure 2 DNAse-gold labelling on Lowicryl sections for nuclear envelope associated chromatin in FDCP-Mix cells treated with $4 \mu \mathrm{M}$ etoposide for $24 \mathrm{~h}$. In contrast to untreated controls (Figure 1), DNAse-gold labelling is intense throughout the nucleolus. (a) In some cells, despite the increase in nucleolar DNA labelling, a clear separation still exists between the nucleolus $(\mathrm{N})$ and the more intensely labelled heterochromatin $(\mathrm{H})$, which is attached to the NE (arrowheads). (b) In other cells, the border between the heterochromatin and the nucleolus is less apparent in both morphology and labelling for DNA Arrowheads mark heterochromatin bridges, which mediate the contact between the nucleolus and the NE. Bars, $500 \mathrm{~nm}$

would be a way to transform a heterogeneous nucleolus (consisting of dense fibrils, dense fibrilar centres, granular components and interstices ${ }^{1,2}$ into a homogenous mass. Despite the stochastic nature of apoptosis and the short execution phase ${ }^{24}$ some details of the nuclear segregation during apoptosis were obtained from conventional thin sections. (1) Segregation of nucleoli may start early before the nucleus shows electron dense material adjacent to the NE. Dense fibrillar centres may be released early (Figure 4) whereas free electron dense fibrils were observed only in cells with apoptotic nuclear morphology (Figures 6 and 7).

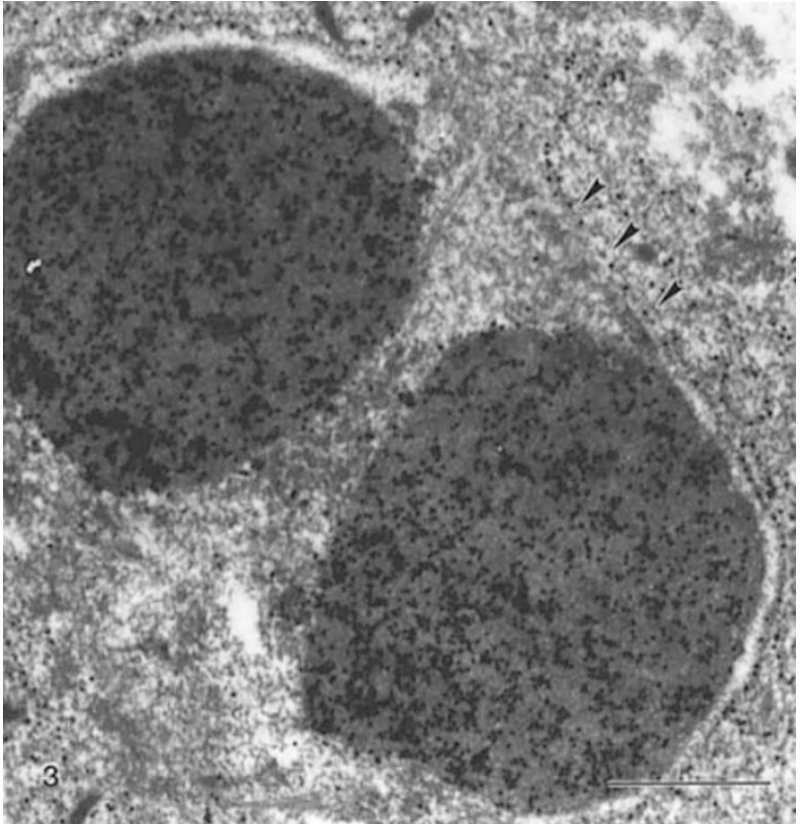

Figure 3 DNAse-gold labelling on a Lowicryl section of an apoptotic FDCPMix cell treated with $4 \mu \mathrm{M}$ etoposide for $24 \mathrm{~h}$. Intense labelling of electron dense material, which correlates to typical electron dense marginations of apoptotic FDCP-Mix nuclei in epoxy resin sections. The labelling is unequally distributed. Some particularly intense labelling at the nucleoplasmic periphery may correlate with the associated caps not apparent in this preparation, but which can regularly be seen in epoxy resin sections. The NE displays characteristic blistering in regions adjacent to the marginations. The presumed location of the NE between the marginations is marked by arrowheads. The background cytoplasmic labelling might be caused by a property of DNAsegold which allows it also to bind to actin. Bar, $500 \mathrm{~nm}$

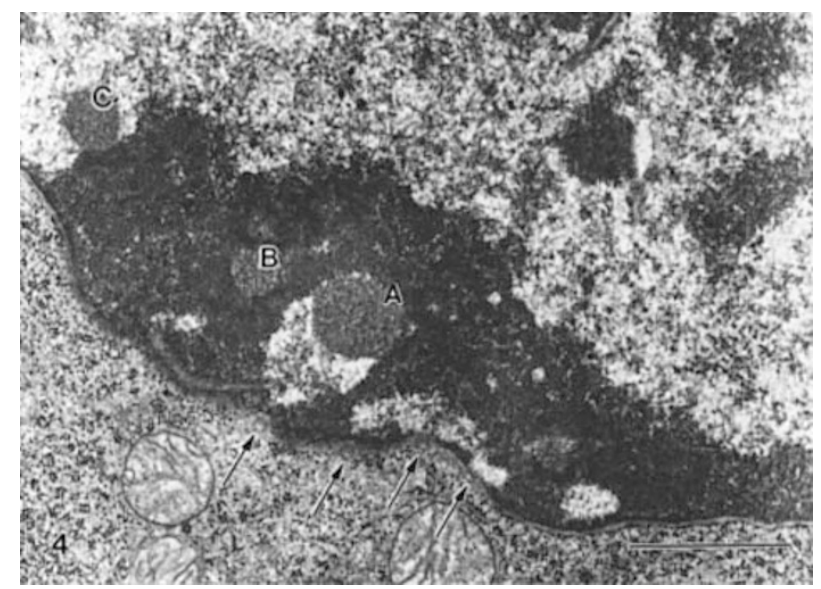

Figure 4 FDCP-Mix cells $(2 \mu \mathrm{M}$ etoposide, $6 \mathrm{~h})$ conventional fixation and embedding. Nucleolar segregation in FDCP-Mix for a nucleolus in association with the nuclear membrane. Circular profiles, which possibly represent the globular fibrilar centres appear to become segregated from the dense fibrilar areas and then released into the nucleoplasm. Circular profile ' $A$ ' is only partially surrounded by nucleolar components whereas circular profile ' $B$ ' is surrounded by dense fibrils. Circular profile ' $C$ ' at the nucleolar periphery is only in loose contact and appears largely 'released' into the nucleoplasm. NPCs which co-localise with the heterochromatin-free 'pockets' are indicated by arrows, two of which are recognised as rings, due to the tangential plane of section. Bar, $1 \mu \mathrm{m}$ 
(2) Although sparsely represented within the cell population, nucleoli could be found associated with the NE which

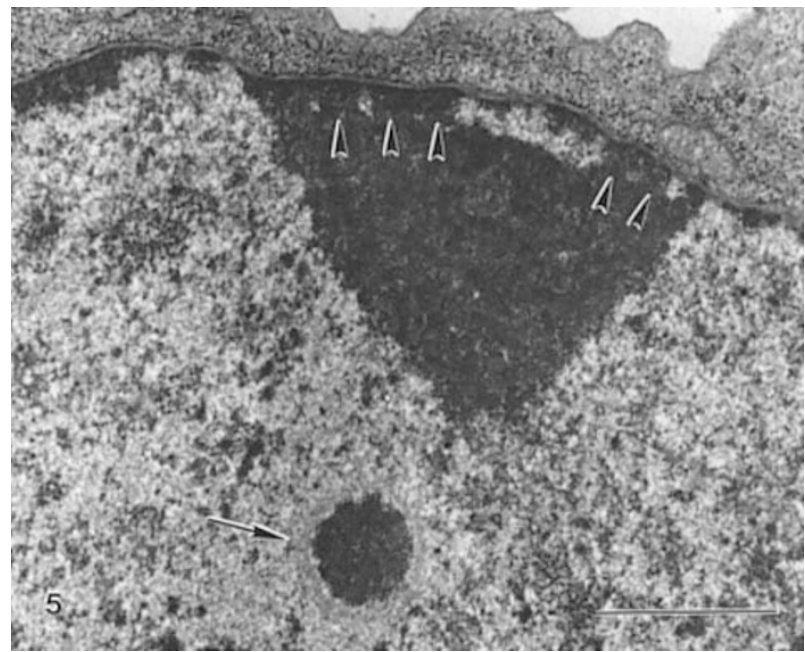

Figure 5 FDCP mix cells $(2 \mu \mathrm{M}$ etoposide, $6 \mathrm{~h})$, conventional fix and embedding. Thin section of a marginated nucleolus attached to the NE, with attachment mediated with bridges of heterochromatin (arrowheads). The nucleolus displays an electron dense but heterogenous overall appearance. Note also a circular profile of granules surrounded by fibrillar material (arrow). Bar 1, $\mu \mathrm{m}$

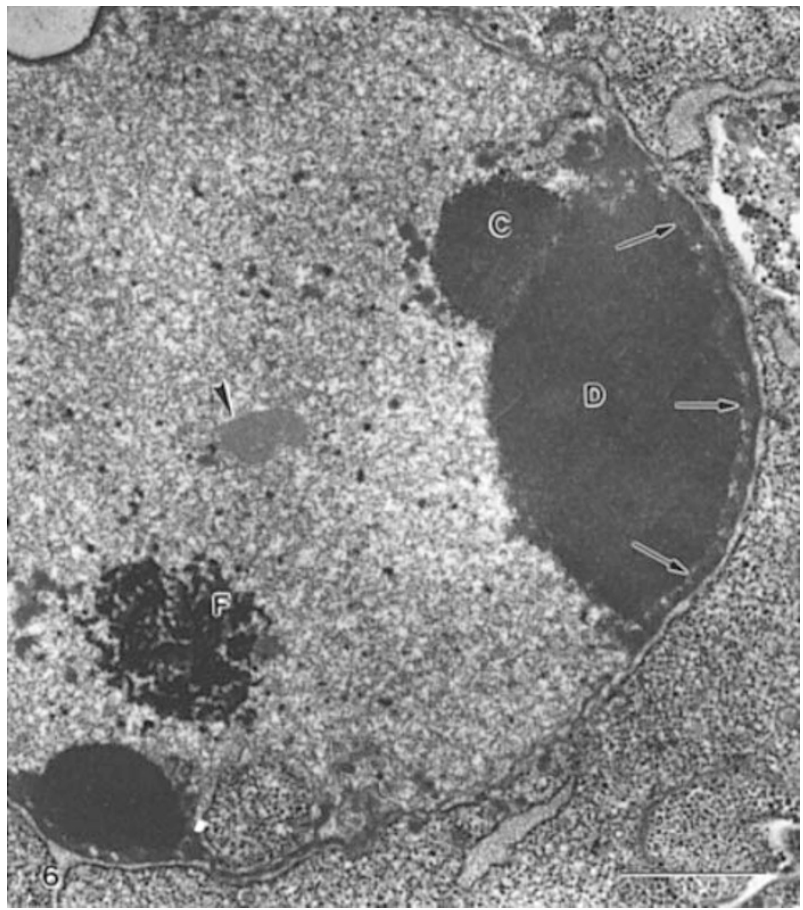

Figure 6 FDCP-Mix cells $24 \mathrm{~h}$ after depletion of IL-3, conventional fix and embedding. Identification of a layer likely to originate from heterochromatin between the electron dense margination (D) and the nuclear envelope. The borders between the layer and the electron dense margination are marked by arrows. A cap $(C)$ consisting of granular material is attached to the periphery of the electron dense material. Large amounts of dense fibrils $(F)$ are aggregated close to another region of dense margination. A crystalline inclusion (arrowhead) is also visible. Bar $500 \mathrm{~nm}$ appeared to be compacted and electron dense, but still heterogenous with dense fibrils inside (Figure 5). They might be regarded as an intermediate stage leading to electron dense margins. Dense fibrils appear to be segregated later in the process (see (4)). (3) Scoring of larger numbers of electron dense marginations in FDCP. Mix, showed association with the NE mediated by a heterochromatin layer (Figure 6). The heterochromatin origin of this layer in apoptotic cells was indicated by residual heterochromatin-free 'pockets' and chromatin bridges between the electron dense margination and the NE. Moreover, we found 'pockets' within the electron dense marginations (Figure 6b), adjacent to nuclear pore complexes. (4) Electron dense fibrils could be found not only outside but also inside the electron dense material of apoptotic FDCP-Mix cells (Figure 7). The release of these fibrils is likely to be a part of a segregation process, which leaves caps behind, which become attached to the nucleoplasmic margin of the electron dense material (Figure 7). Whereas cap structures attached to the

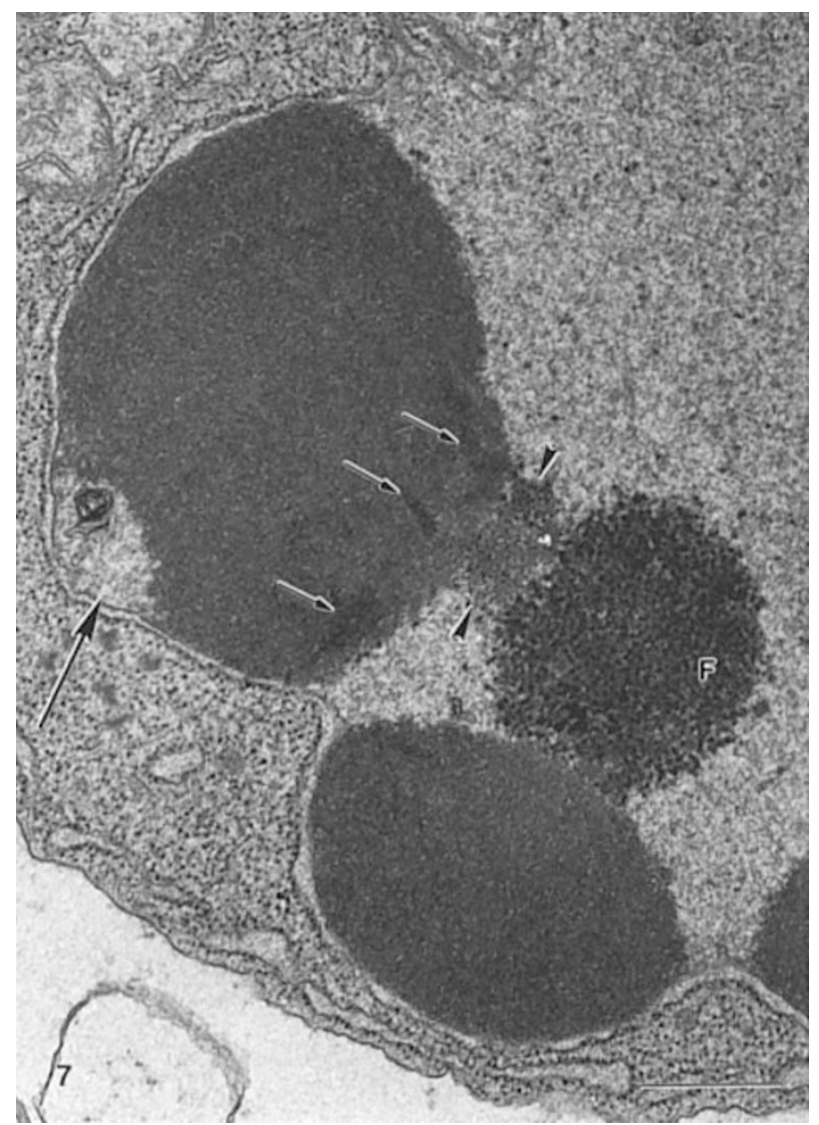

Figure 7 FDCP-Mix cells $24 \mathrm{~h}$ after depletion of IL-3, conventional fixation and embedding. Detail of the segregation process which involves an electron dense margination of an apoptotic FDCP-Mix nucleus. The electron dense margination of likely nucleolar origin has granules of increased electron density at the periphery (small arrows). A granular cap (arrowheads) may be in the process of formation between the electron dense margination and an aggregation of dense fibrils $(F)$ as a consequence of the segregation process. Although a chromatin layer can not be identified between the NE and the electron dense margination, a typical 'pocket' can be observed (large arrow). Bar, $1 \mu \mathrm{m}$ 


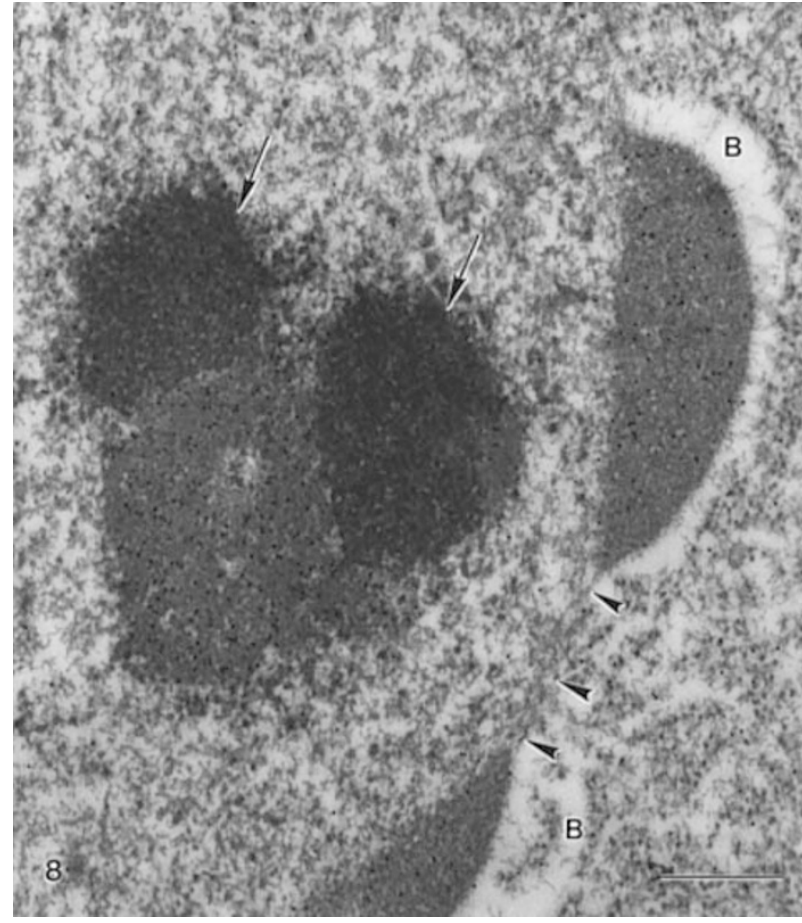

Figure 8 Detail of an apoptotic FDCP-Mix nucleus (withdrawal of IL-3, 24 h) which has been labelled by RNAse-gold in Lowicryl section. Electron dense marginations adjacent to the 'blistered' $N E(B)$ show significant labelling by RNAse-gold. The continuity of the NE between the blistered areas is labelled by arrowheads. An electron dense margination within the nucleoplasm is associated with two large dark caps (arrows). The segregation between the caps and the margination is not only apparent by its texture and electron density, but also by reduced labelling of the caps for RNA. Bar, $200 \mathrm{~nm}$

electron dense material can be observed regularly ${ }^{7,15}$ the segregation of dense fibrils in marginations was observed only rarely.

In addition to our morphological observations, we labelled apoptotic FDCP-Mix cells by RNAse-gold complexes (Figure 8). The labelling suggests that the electron dense material adjacent to the NE contains reasonable amounts of ribonucleic acids and therefore is by no means a homogenous aggregation of condensed chromatin alone.

\section{Discussion}

\section{What happens to the chromatin when the nucleolus segregates?}

Our results for FDCP-Mix demonstrate that a clear separation between the events of chromatin condensation and nucleolar segregation during apoptosis cannot be taken for granted. Combined studies of morphology and enzyme gold techniques $^{17,20}$ showed that nucleolar components contribute significantly to the content of the electron dense marginations in FDCP-Mix. Therefore, there is no reason to suggest that electron dense marginations in FDCP-Mix, which are regarded as typical for apoptosis in haemopoietic stem cells, ${ }^{25}$ represent only condensed chromatin. A condensation of chromatin within these structures appears to be spec- ulative. Moreover, it is not supported by the hypothesis that chromatin in a condensed stage allows only limited binding for DNAse-gold. ${ }^{17}$ Although the restrictions for the labelling of heterochromatin and peripheral nucleolar chromatin can be prevented by preparative measures including the preincubation with DNAse at $37^{\circ} \mathrm{C}^{20}$ (and our protocol), these measures might not be enough for a supposed condensed stage of chromatin during apoptosis. Interestingly, etoposide-treated apoptotic MOLT-4 cells differ not only from FDCP-Mix by their potential to form double-membraned micronuclei and by the peripheral arrangement and the fine structure of the electron dense material, in which DNA is fragmented, ${ }^{15}$ but also in details of the nucleolar segregation.

In MOLT-4 an initial increase in electron density of the nucleolus is accompanied by hypertrophy and an apparent decrease in the electron density of the nucleoplasm. ${ }^{21}$ Later on, larger amounts of electron dense material are accumulated at the margin of the micronuclei and the nucleolus loses its contact with the condensed material at the nuclear periphery, gets segregated, and disintegrates. During this process it also loses electron density relative to the electron dense material at the nuclear periphery. We come to the conclusion, that experimental systems used in apoptosis research can significantly differ in the way how the nucleolus segregates and disintegrates. Chromatin condensation might play a role during apoptosis but it is unlikely to be a universal process.

\section{Is the entry of DNA into the nucleolus a common event during cell death?}

Recently, DNAse-gold labelling has been applied to apoptotic HL-60 cells by Falcieri et al. ${ }^{26}$ In results restricted to cells with an apoptotic morphology, this technique confirmed that the electron dense material in HL-60 contains DNA (an observation which has also been made by osmium ammine staining and subsequent acidic hydrolysis of RNA).

By comparison of DNAse-gold labelling for both untreated FDCP-Mix controls and etoposide treated FDCP-Mix we observed the apparent insertion of DNA into the bulk of the nucleolus at a stage where the FDCP. Mix nucleus has yet to assume a typical apoptotic morphology.

The observation that DNA enters the bulk of nucleoli in FDCP-Mix at a stage where the nuclear morphology still appears perfectly non-apoptotic raises more questions than it can answer. First of all one would like to know whether this is a general principle of apoptotic cell death. Secondly, one has to address the question as to whether this process is related to the DNA fragmentation during apoptosis (for review: ${ }^{27}$ ) (Is DNA fragmentation the precondition, a result, or not related at all?). The investigation of the spatial distribution of intracellular DNA fragmentation by in situ 3' end labelling of DNA breaks in K562 cells indicate that, at an early stage, the nucleolus might be excluded from DNA breaks. However, intense labelling for fragmented DNA has been reported in the more advanced stages, which corresponded to the so-called chromatin condensation in the electron microscope. ${ }^{28}$ Preliminary results with etoposide treated MOLT4 cells could not find similar qualitative 
observations of a DNA 'uptake' at an early stage. ${ }^{21}$ However, the segregation process of the nucleoli in MOLT4 differs significantly in its morphological steps from FDCP-Mix. Therefore, we cannot exclude that DNA 'uptake' is present in a tiny subfraction of the apoptotic population of MOLT4 which has not been spotted yet. Comparative studies of DNAse gold labelling in MOLT4 cells showed that it is unlikely that etoposide has a general effect on the accessibility of DNAse-gold label to ribosomal DNA. Moreover, the studies of the crescent electron dense material of MOLT4 gave a hint that highly condensed chromatin in apoptotic cells might be less accessible for labelling by DNAse-gold than heterochromatin. Restricted access for DNAse-gold to heterochromatin has been reported by Bendayan. ${ }^{17}$ Preparative measures including the preincubation with DNAse at $37^{\circ} \mathrm{C}^{20}$ (and our protocol), might not be sufficient to allow access for the gold labelling of chromatin at an even more condensed stage.

\section{What is the functional impact of the association of the nucleolus and the NE?}

Under physiological conditions, the nucleoli of mouse of the somatic cells are arranged in contact with the nuclear envelope (NE) (for review: ${ }^{22}$ ). Nucleoli which display their association with the NE in thin sections have been named 'nucleolar marginations'. ${ }^{23}$ The local relationship between nucleoli and the NE and its nuclear pore complexes (NPCs) has been suggested as a favourable configuration for organisation of the transfer of mRNA transcripts to the sites of protein synthesis in the cytoplasm. ${ }^{22,23}$ When cells are confronted with a large demand for ribosomes, e.g. during phytohemagglutinin activation or in regenerating rat hepatocytes, the strategy adopted by somatic cells is to increase the number of nucleoli. ${ }^{29,30}$ Although a quantification of the number of nucleoli associated to the NE of FDCP-Mix mix cells was not part of our work, such a scenario is likely to happen for them, too. We found qualitatively, that treatment of FDCP-Mix with etoposide and the depletion of IL-3 growth factor do not result in a loss of nucleolar contact to the NE in the 'commitment phase' of apoptosis. ${ }^{24}$ As demonstrated for FDCP-Mix, even during the 'execution phase',24 this link is not necessarily cut off. Traces of 'chromatin-free pockets' between electron dense remnants of the nucleolus and the NE in apoptotic FDCP-Mix and their co-localisation with with NPCs ${ }^{15}$ suggest that the facilities for translocation in association with the nucleolus are maintained as long as possible. In contrast to FDCP-Mix, in apoptotic micronuclei of MOLT- $4^{15,21}$ we found that the nucleoli lose their contacts to the NE generally at a late state of apoptosis, which is marked by the segregation of dense fibrils. Since we could only reconstruct the likely sequence of the events of nucleolar segregation in association with the nuclear membrane and the signs for a nucleolar origin of any electron dense material were not equally well maintained in the plane of the section, we cannot exclude that some of the electron dense material within an apoptotic FDCP-Mix could also be accumulated by the collapse and condensation of chromatin elsewhere in the nucleus. Therefore it would be interesting to follow the fate of the nucleolar function in different experimental systems to understand how transcription is locally organised in relation to the NE under physiological conditions and also during the course of cell death. For this purpose, the visualisation of transcription sites by immunolabelling with $\mathrm{BrUTP}^{31}$ in apoptotic cells could be informative.

\section{How light microscopy can contribute to studies of the nucleolar segregation during apoptosis}

It is known that fluorophores for the staining of nucleic acids (e.g. propidium iodide, acridine orange, DAPI, TOPRO1) stain nucleoli in cells which have been maintained under physiological conditions. However, no efforts have been made to trace the nucleolar segregation during apoptosis in parallel to chromatin condensation. Instead, any DNA positive staining has been interpreted to represent condensed chromatin. Although confocal microscopy for bleomycin treated Chinese hamster fibroblasts stained by PI contains details, which, for our view, support the idea of a DNA uptake by nuclear membrane attached nucleoli, Tounekti et $a l^{10}$ interpret them as chromatin condensation. This example demonstrates that single staining for DNA is not adequate to deal with our hypothesis, which suggests a DNA uptake by nucleoli during apoptosis. Double staining by both a DNA marker and a specific nucleolar marker is needed to tackle the problem. Those studies may include nucleolar nuclear matrix proteins, e.g. the $180-\mathrm{kDa}$ nucleolar isoform of DNA topoisomerase II. $^{32}$ It has been reported by Zweyer ${ }^{32}$ that the fluorescence patterns of the nucleolar isoform of topoisomerase II are well-maintained until the late phase of apoptosis in HL-60 human leukaemia cells.

In summary, our results indicate that the segregation of the nucleolus is likely to be the overriding process which is responsible for the overall apoptotic morphology of the nucleus. The formation of electron dense material during this process could be easily mistaken as chromatin condensation, since DNA is a major constituent of it. Our observations for FDCP-Mix contradict the general interpretation of electron dense material as 'condensed chromatin' and the current use of this term as a hallmark of apoptosis. They may attract attention towards the nucleolar segregation during apoptosis in other experimental systems. For our point of view, this would help overcome, what has been named frankly by Kerr ${ }^{9}$ as an area of neglected opportunities in apoptosis research.

\section{Materials and Methods}

\section{Cell culture}

The FDCP-Mix cell line is a pluripotent haemopoietic stem cell derived from long term cultures of mouse bone marrow. ${ }^{12,13}$ These cells are nonleukaemic and karyotypically normal and are dependent upon interleukin-3 (IL-3) for their survival and self-renewal. Cells were routinely maintained in Iscove's medium supplemented with $20 \%$ horse serum and $2 \%$ conditioned medium from X63Ag8-653 cells as a source of IL-3. ${ }^{33}$ The cells were plated at $5 \times 10^{3} / \mathrm{ml}$ in culture medium. 
For drug treatment, cells were incubated in the presence of etoposide (VP-16, Sigma, UK). Depletion of IL-3 was performed as described elsewhere. $^{13}$

\section{Flow cytometry}

Flow cytometric analyses were carried out using a Coulter Epics $V$ flow cytometer and cellsorter. The computer analysis of the data was performed using the Epics analysis package of the Paterson Institute (S. Roberts, unpublished data). For some analyses the Becton Dickinson FACS Vantage System was used. The FACS Vantage data analyses were performed using the software package PCLYSIS.

For the discrimination of viable, apoptotic and necrotic cells, a rapid multiparameter assay was used, measuring forward light scatter (FSC) in combination with the DNA-binding fluorophores Hoechst 33342 and propidium iodide. In brief, Hoechst $33342(10 \mu \mathrm{M})$ and propidium iodide $(32 \mu \mathrm{M})$ were added to cell suspensions $\left(2-3 \times 10^{5}\right.$ in $0.5 \mathrm{ml}$ phosphate-buffered saline). $1 \times 10^{4}$ cells were analyzed 2 min after staining, using an ultraviolet laser excitation (100 or $50 \mathrm{~mW}$ ) at about $357 \mathrm{~nm}$. FSC, blue fluorescence (Hoechst-DNA, log scale, between $420-560 \mathrm{~nm}$ ) and red fluorescence (propidium iodideDNA/RNA; linear scale, about $630 \mathrm{~nm}$ ) were recorded for each cell investigated. Cell debris were excluded electronically. Data were analyzed as two dimensional frequency plots of FSC (cell size) versus log blue fluorescence, following exclusion of red (necrotic) cells. Typically, two clearly separated populations could be distinguished: viable cells, which displayed high FSC and low blue fluorescence (Hoechst staining), and apoptotic cells, which displayed lower FSC and higher blue fluorescence.

\section{DNA gel electrophoresis}

Samples for conventional gel electrophoresis were prepared, with minor modifications, as described elsewhere. Briefly, $1 \times 10^{6}$ cells were resuspended in $20 \mu$ l of lysis buffer (10 mM EDTA, $50 \mathrm{mM}$ Tris $\mathrm{HCl}$ at $\mathrm{pH} 8,0.5 \%$ sodium lauryl sarcosinate and $0.5 \mathrm{mg} / \mathrm{ml}$ proteinase $\mathrm{K}$ ) and incubated for $1 \mathrm{~h}$ at $50^{\circ} \mathrm{C}$. Samples were incubated for a further $3 \mathrm{~min}$ at $70^{\circ} \mathrm{C}$. Subsequently, $10 \mu \mathrm{l}$ of bromphenolblue dye in $40 \%$ sucrose was added. The samples and a DNA marker $(0.1-100 \mathrm{kbp})$ (Sigma, UK) were loaded into wells of a $1.5 \%$ agarose gel. The wells were sealed with $1.5 \%$ low melting point agarose. Samples were allowed to solidify before the gel was flooded with $0.5 \times$ TBE buffer (4 $\mathrm{mM}$ tris, $45 \mathrm{mM}$ boric acid, $0.5 \mathrm{mM}$ EDTA) and subjected to electrophoresis at $50 \mathrm{~V}$. The gel was stained with ethidium bromide $(0.5 \mu \mathrm{g} / \mathrm{ml})$. DNA was visualised using a UV transilluminator.

\section{Electron microscopy}

Epoxy resin embedding Cell pellets were fixed in $2.5 \%$ glutaraldehyde in $0.15 \mathrm{M}$ Sorensen's buffer $(\mathrm{pH} 7.4)$ for $1 \mathrm{~h}$. After three buffer washes the pellets were postfixed in $1 \% \mathrm{OsO}_{4}$ in Sorensen's for $1 \mathrm{~h}$. Subsequently, the pellets were dehydrated in ethanol and embedded in epoxy resin (Agar 100). Thin sections 60-80 nm thick were mounted on copper grids, stained in uranyle acetate and lead citrate, and viewed at $80 \mathrm{kV}$ in the TEM.

Lowicryl embedding For DNAse-gold labelling, cell pellets were fixed in $4 \%$ paraformaldehyde and $0.1 \%$ glutaraldehyde in $100 \mathrm{mM}$ PBS $(\mathrm{pH} 7.4)$ for $1 \mathrm{~h}$. The fixed pellets were rinsed in PBS and dehydrated in a ethanol series at $-20^{\circ} \mathrm{C}$. Ethanol was replaced by Lowicryl HM2O. Lowicryl was $\mathrm{N}_{2}$-bubbled to remove $\mathrm{O}_{2}$ and screw-capped vials were used to avoid its contact with air. Finally, the samples were transferred into transparent beam capsules, which were filled with freshly prepared Lowicryl. Polymerisation was complete after $24 \mathrm{~h}$ UV-light exposure at $-30^{\circ} \mathrm{C}$. Thin Lowicryl sections $60-80 \mathrm{~nm}$ thick were mounted on nickel grids.

RNAse- and DNAse-gold labelling has been described in detail elsewhere. ${ }^{16-19}$

RNAse-gold labelling RNAse-gold was provided as a conjugate of $10 \mathrm{~nm}$ gold particles to RNAse A (Type XII-A: bovine pancreas, Sigma) in $2.0 \mathrm{mM}$ sodium borate buffer, at the optimal $\mathrm{pH}(\mathrm{pH} 8.5-9)$ for enzyme-gold binding (E-Y Laboratories, Inc., USA). Before use, it was centrifuged at $400 \times g$ for $10 \mathrm{~min}$ to remove aggregates of gold particles. The enzyme-gold stock solution was diluted 1:10 in PBS containing $0.02 \%(0.2 \mathrm{mg} / \mathrm{ml})$ polyethylene glycol (PBS+PEG) at the optimal $\mathrm{pH}$ for RNAse activity $(\mathrm{pH} 7.2-7.4)$. The grids were floated sections down for $5 \mathrm{~min}$ on a drop of PBS+PEG. This pretreatment was followed by $30 \mathrm{~min}$ incubation with RNAse-gold $(1: 10)$ in a wet chamber at $37^{\circ} \mathrm{C}$. The grids were thoroughly washed in PBS, pH 7.4, rinsed in ddw and subsequently stained with uranyl acetate and lead citrate.

For control, samples were preincubated in $10 \mathrm{mg} / \mathrm{ml}$ RNAse A for $45 \mathrm{~min}$ at $37^{\circ} \mathrm{C}$ before incubation with RNAse-gold or RNAse-gold/ RNAse in a ratio $1: 1$ (prepared 15 min before at room temperature) in a wet chamber at $37^{\circ} \mathrm{C}$.

DNAse-gold labelling DNAse-gold was provided as a conjugate of $10 \mathrm{~nm}$ gold particles to DNAse I in distilled water, $\mathrm{pH} 7.0$ (E-Y Laboratories, Inc., USA). The enzyme-gold stock solution was diluted $1: 10$ in PBS containing $0.02 \%(0.2 \mathrm{mg} / \mathrm{ml})$ polyethylene glycol (PBS+PEG) at the optimal $\mathrm{pH}$ for DNAse activity $(\mathrm{pH} \mathrm{6.0)}$. After preincubation in PBS+PEG ( $\mathrm{pH} 6.0)$ for $5 \mathrm{~min}$, samples were incubated in DNAse I (Boehringer)/DNAse I-gold for $45 \mathrm{~min}$ in a wet chamber at $37^{\circ} \mathrm{C}$. (DNAse I/DNAse l-gold was prepared $15 \mathrm{~min}$ before use at a ratio $1: 1$ and kept at room temperature). For control, samples were incubated with DNAse I for $30 \mathrm{~min}$ at $37^{\circ} \mathrm{C}$ before incubation with DNAse I/DNAse-gold (1:1).

The sections were counterstained with uranyl acetate and lead citrate, and viewed at $80 \mathrm{kV}$ in a Philips electron microscope (Philips EM 400).

\section{Acknowledgements}

This work was supported by the Cancer Research Campaign, UK and the Wellcome Trust, UK. SR is a recipient of a Wellcome Trust studentship.

\section{References}

1. Jordan EG (1991) Interpreting the nucleolar structure: where are the transcribing genes. J. Cell. Sci. 98: 437-442

2. Hozák P (1995) Catching RNA polymerase I in flagranti: Ribosomal genes are transcribed in the dense fibrillar component of the nucleolus. Exp. Cell Res. 216: 285-289

3. Mélèse T and Xue Z (1995) The nucleolus: a organelle formed by the act of building a ribosome. Curr. Opin. Cell. Biol. 7: 319-324

4. Bernard W (1971) Drug-induced changes in the interphase nucleus. Advances in cytopharmacology 1, First International Symposium on Cell Biology and Cytopharmacology New York: Raven Press

5. Brasch K (1990) Drug and metabolite-induced perturbations in nuclear and function. A review. Biochem. Cell. Biol. 68: 408-426

6. Wyllie AH, Kerr JFR and Currie AR (1980) Cell death: The significance of apoptosis. Int. Rev. Cytol. 68: 251-306

7. Arends MJ, Morris RG and Wyllie AH (1990) Apoptosis. The role of the endonuclease. Am. J. Pathol. 136: 593-608 
8. Wyllie AH (1992) Apoptosis and the regulation of cell numbers in normal and neoplastic tissue: an overview. Cancer Metastasis Rev. 11: 95-103

9. Kerr JFK (1995) Neglected opportunities in apoptosis research. Trends Cell. Biol. 5: 55-57

10. Tounekti O, Belehradek J and Mir LM (1995) Relationship between DNA fragmentation, chromatin condensation, and changes in flow cytometric profiles detected during apoptosis. Exp. Cell. Res. 217: 506-516

11. Falcieri E, Gobbi P, Zamai L, Faenza I and Vitale M (1994) Nuclear pores in the apoptotic cell. Histochem. J. 26: 754-763

12. Spooncer E, Heyworth CM, Dunn A and Dexter TM (1986) Self-renewal and differentiation of interleukin-3-dependent multipotent stem cells are modulated by stromal cells and serum factors. Differentiation 31: 111-118

13. Fairbairn LJ, Cowling GJ, Reipert BM and Dexter TM (1993) Suppression of apoptosis allows differentiation and development of a multipotent hemopoietic cell line in the absence of added growth factors. Cell 74: 823-832

14. Fairbairn LJ, Cowling GJ, Dexter TM, Rafferty JA, Margison GP and Reipert BM (1994) bcl-2 delay of alkylating agent-induced apoptotic death in a murine hemopoietic stem cell line. Mol. Carcinog. 11: 49-55

15. Reipert S, Reipert BM, Hickman JA and Allen TD (1996) Nuclear pore clustering is a consistent feature of apoptosis in vitro. Cell Death Differ. 3: 131-139

16. Reipert S, Hickman JA and Allen TD (1996) DNA inclusions within autolytic cytoplasmic vacuoles of hemopoietic stem cell line FDCP-Mix. J. Histochem Cytochem. 44: $549-558$

17. Bendayan M (1981) Ultrastructural localization of nucleic acids by the use of enzyme-gold complexes. J. Histochem. Cytochem. 29: 531-541

18. Thiry M (1988) Study of RNA distribution on the nucleolar components of Ehrlich cell using RNase-gold method. Histochem. 89: 231-236

19. Mikhaylova VT, Thiry M, Stephanova E, Goessens G and Markov DV (1996) Localisation of nuclei acids in hepatocyte nuclei of rats upon D-galactosamineinduced block of transcription. Exp. Cell Res. 225: 389-398

20. Bendayan M (1989) The enzyme-gold cytochemical approach: a review. In: Colloidal Gold: Principles, Methods, and Applications 2nd edn, MA Hayated. Vol. 2, (San Diego: Academic Press) pp 117-148

21. Reipert S (1996) Ultrastructural studies of drug-induced apoptosis. PhD Thesis, University of Manchester
22. Bourgeois CA and Hubert J (1988) Spatial relationship between the nucleolus and the nuclear envelope: structural aspects and functional significance. Int Rev. Cytol. 111: 1-52

23. Ghadially FN (1988) Ultrastructural Pathology of the Cell and Matrix. 3rd edn. (London: Butterworths)

24. Earnshaw WC (1995) Apoptosis: lessons from in vitro systems. Trends Cell Biol. 5: $217-220$

25. Williams GT, Smith CA, Spooncer E, Dexter TM and Taylor DR (1990) Haempoietic colony stimulating factors promote cell survival by suppressing apoptosis. Nature 343: 76-79

26. Falcieri E, Zamai L, Santi S, Cinti P, Gobbi P, Bosco D, Cataldi A, Betts C and Vitale M (1994) The behaviour of nuclear domains in the course of apoptosis. Histochem. 102: 221-231

27. Bortner CD, Oldenburg NBE and Cidlowski JA (1995) The role of DNA fragmentation in apoptosis. Trends Cell Biol. 5: 21-26

28. Kressel M and Groscurth P (1994) Distinction of apoptotic and necrotic cell death by in situ labelling of fragmented DNA. Cell Tissue Res. 278: 549-556

29. Hadjiolov AA (1985) The nucleus and ribosome biogenesis. Berlin: SpringerVerlag

30. Wachtler F, Hopman AH, Weigant $J$ and Schwarzacher HG (1986) On the position of the nucleolus organizer regions (NORs) in the interphase nuclei. Studies with a new, non-autoradiographic in situ hybridization method. Exp. Cell Res. 167: $227-240$

31. Jackson DA, Hassan AB, Errington RJ and Cook PR (1993) Visualization of focal sites of transcription within human nuclei. EMBO J. 12: 1059-1065

32. ZweyerM, Bareggi R, Grill V, Scoranzo Mr, Marugg RA, RiedererBM, NarducciP and Martelli AM (1995). Behavior of nuclear matrix proteins during camptohecininduced apoptosis in HL-60 human leukemia cells. Exp. Cell Res. 221: 27-40

33. Karasuyama $\mathrm{H}$ and Melcers $F$ (1988) Establishment of mouse cell lines which constitutively secrete large quantities of interleukin 2, 3, 4, or 5 using modified cDNA expression vectors. Eur. J. Immunol. 18: 97-107

34. Heyworth CM, Dexter TM, Kan O and Whetton AD (1990) The role of the hemopoietic growth factors in self-renewal and differentiation of IL-3-dependent multipotential stem cells. Growth Factors 2: 197-211 